\title{
Individual and Community Factors Associated with Naloxone Co-prescribing Among Long-term Opioid Patients: a Retrospective Analysis
}

\author{
Bradley D. Stein, MD, $P h D^{1,2}$ (D), Rosanna Smart, $P h D^{3}$, \\ Christopher M. Jones, PharmD, DrPH ${ }^{4}$, Flora Sheng, MPH ${ }^{5}$, David Powell, $P h D^{5}$, and \\ Mark Sorbero, $\mathrm{MS}^{\mathrm{l}}$ \\ 'RAND Corporation, Pittsburgh, PA, USA; ${ }^{2}$ University of Pittsburgh School of Medicine, Pittsburgh, PA, USA; ${ }^{3}$ RAND Corporation, Santa Monica, CA, \\ USA; ${ }^{4}$ Centers for Disease Control and Prevention, Atlanta, GA, USA; ${ }^{5}$ RAND Corporation, Arlington, VA, USA.
}

BACKGROUND: Naloxone co-prescribing to individuals at increased opioid overdose risk is a key component of opioid overdose prevention efforts.

OBJECTIVE: Examine naloxone co-prescribing in the general population and assess how co-prescribing varies by individual and community characteristics.

DESIGN: Retrospective cross-sectional study. We conducted a multivariable logistic regression of 2017-2018 de-identified pharmacy claims representing 90\% of all prescriptions filled at retail pharmacies in 50 states and the District of Columbia.

PATIENTS: Individuals with opioid analgesic treatment episodes $>90$ days

MAIN MEASURES: Outcome was co-prescribed naloxone. Predictor variables included insurance type, primary prescriber specialty, receipt of concomitant benzodiazepines, high-dose opioid episode, county urbanicity, fatal overdose rates, poverty rates, and primary care health professional shortage areas.

KEY RESULTS: Naloxone co-prescribing occurred in $2.3 \%$ of long-term opioid therapy episodes. Medicaid (aOR 1.87, 95\%CI 1.84 to 1.90) and Medicare (aOR 1.48, $95 \%$ CI 1.46 to 1.51 ) episodes had higher odds of naloxone co-prescribing than commercial insurance episodes, while cash pay (aOR $0.77,95 \%$ CI 0.74 to 0.80 ) and other insurance episodes (aOR $0.81,95 \%$ CI 0.79 to 0.83 ) had lower odds. Odds of naloxone co-prescribing were higher among high-dose opioid episodes (aOR 3.19, 95\%CI 3.15 to 3.23), when concomitant benzodiazepines were prescribed (aOR 1.12, 95\%CI 1.10 to 1.14 ), and in counties with higher fatal overdose rates.

CONCLUSION: Co-prescription of naloxone represents a tangible clinical action that can be taken to help prevent opioid overdose deaths. However, despite recommendations to co-prescribe naloxone to patients at increased risk for opioid overdose, we found that co-prescribing rates remain low overall. States, insurers, and health systems should consider implementing strategies to

Prior Presentations None

Supplementary Information The online version contains supplementary material available at https://doi.org/10.1007/s11606-020-06577-5.

Received August 7, 2020

Accepted December 29, 2020

Published online February 17, 2021 facilitate increased co-prescribing of naloxone to at-risk individuals.

KEY WORDS: opioids; naloxone; overdose prevention; prescribing.

J Gen Intern Med 36(10):2952-7

DOI: $10.1007 / \mathrm{s} 11606-020-06577-5$

(C) This is a U.S. government work and not under copyright protection in the U.S.; foreign copyright protection may apply 2021

\section{INTRODUCTION}

Prescription opioid analgesics were involved in nearly 15,000 overdose deaths in 2018. ${ }^{1}$ Patients receiving long-term opioid therapy, especially at higher doses, are at an increased risk for opioid overdose. ${ }^{2-4}$ As a result, the 2016 CDC Guideline for Prescribing Opioids for Chronic Pain, the U.S. Department of Health and Human Services, and professional organizations have issued recommendations that clinicians consider coprescribing naloxone to such patients. ${ }^{5-7}$ Naloxone, a shortacting opioid antagonist effective in reversing opioid overdose-related central nervous system and respiratory depression, ${ }^{8}$ is a key component of opioid overdose prevention efforts. Recent research has demonstrated that naloxone being distributed by pharmacies is associated with decreased overdose deaths. ${ }^{9}$

While overall rates of naloxone prescribing remain low, ${ }^{10,11}$ in recent years, there has been a substantial increase in naloxone prescriptions filled in pharmacies. ${ }^{12-14}$ In addition, an increasing number of states have passed laws requiring co-prescription of naloxone to patients receiving high-dose opioids or who have opioids and benzodiazepines concomitantly prescribed. ${ }^{14}$ Studies of overall naloxone prescribing in the general population have found that primary care physicians, nurse practitioners/ physician assistants, and pain/anesthesia physicians are responsible for most naloxone prescribing. ${ }^{11,15}$ Females and older individuals appear more likely to receive dispensed naloxone prescriptions, ${ }^{13,15}$ with almost half of naloxone prescriptions filled by individuals over age $50 .{ }^{15}$

With respect to naloxone co-prescribing among patients receiving opioid analgesics, studies using Medicare Part D 
data have found that even among the top $1 \%$ of opioid prescribers, fewer than $5 \%$ prescribed naloxone to more than 10 Medicare patients, ${ }^{11}$ and fewer than $1 \%$ of Medicare Part D beneficiaries filling an opioid analgesic prescription had naloxone co-prescribed. ${ }^{10}$ Rates of naloxone co-prescribing among Medicare beneficiaries have increased from 2016 to 2017, with beneficiaries receiving long-term opioid therapy, higher morphine milligram equivalents (MME) dosages per day, or concomitant prescriptions for benzodiazepines exhibiting higher rates of co-prescribing. ${ }^{10}$ However, although more than half of naloxone prescriptions are filled by individuals younger than age 50 , there is a paucity of information regarding naloxone co-prescribing in non-Medicare Part D populations. ${ }^{15}$ Furthermore, while some studies have shown substantial geographic variation in naloxone prescribing and co-prescribing, ${ }^{10,12,13,15}$ they have not examined to what extent community characteristics may be associated with naloxone co-prescribing among patients receiving opioid therapy.

To address these gaps in the literature, we used pharmacy claims from approximately $90 \%$ of US retail pharmacies to examine naloxone co-prescribing among patients in the general population who were receiving long-term opioid therapy and to assess how such co-prescribing varies by individual and community characteristics. Based on prior research, we hypothesized that higher rates of naloxone co-prescribing would be identified among individuals receiving concomitant benzodiazepines or higher MME per day and among metropolitan county residents.

\section{METHODS}

\section{Data and Sample}

To examine naloxone co-prescribing, we used de-identified pharmacy claims from the IQVIA Real World DataLongitudinal Prescriptions. ${ }^{16}$ These data capture an estimated $90 \%$ of all prescriptions filled at retail pharmacies in all 50 states and the District of Columbia and contain information on the prescription, payer, patient demographics, and prescribing provider specialty and location.

To create the sample, we identified all individuals with new opioid treatment episodes lasting longer than 90 days that started in 2017-2018. A new treatment episode started with the first observed fill date of any opioid prescription following a clean period, defined as at least a 30-day period after the day's supply of any prior opioid prescription had run out. An episode lasted through the last day of the supply of medication for the last filled opioid prescription, with no more than a 30day gap between the last day supply of one prescription and the filling of the subsequent prescription. For example, if an individual filled a prescription with a 10-day supply on September 1 , the episode would be considered as having ended on September 10 if there were no opioid prescriptions filled in the 30 days after September 10. As a sensitivity analysis, we repeated the analysis using a 90-day clean period. The results of the sensitivity analysis, which were not meaningfully different than the primary analysis, are provided in the supplementary appendix.

We restricted our analyses to long-term opioid therapy episodes, defined as episodes lasting more than 90 days, and individuals could have more than one long-term opioid episode. Given naloxone has a shelf life of at least 18 months, we also excluded individuals who had filled a naloxone prescription in 2015 and 2016, as they would likely not need a new naloxone prescription unless the prior one had been used. The study was deemed exempt by the corresponding author's Institutional Review Board.

\section{Outcome Measure}

Our outcome measure was co-prescribed naloxone, defined as a filled naloxone prescription at any time during the long-term opioid episode or in the 7 days before the episode began. Among individuals with multiple long-term opioid episodes, any episode subsequent to the first episode in which the individual had naloxone co-prescribed was also categorized as having co-prescribed naloxone, given naloxone's shelf life of at least 18 months.

\section{Predictor Variables}

We categorized long-term episodes as high dose if the MME daily dose exceeded 90 MME on more than 14 days at any time during the episode. Long-term episodes during which a benzodiazepine prescription was filled were categorized as concomitant benzodiazepine therapy.

Prescribers were categorized into five groups according to the responsible prescriber's specialty: adult primary care (including internal medicine and family practice); non-physicians (primarily nurse practitioners and physician's assistants); pain and anesthesia physicians; oncologists; and other specialties. Episodes in which the patient filled opioid prescriptions from 2 or more prescribers were categorized as a multiple prescriber episode and were attributed to the prescriber who wrote the majority of opioid days of supply during the episode.

We categorized patients by gender and age group (12-17 years, 18-25, 26-35, 36-45, 46-55, 56-65, and over 65 years). We determined the primary source of payment for the opioid analgesic episode (Medicaid, Medicare, commercial insurance, cash pay, and other insurance, which included Tricare and prescription discount cards) by the payment source for the majority of the days of supply of opioids during the episode. We used the 5-digit FIPS code of the episode prescriber to determine the county in which the episode occurred. County urbanicity was categorized based on Rural-Urban Continuum Codes (RUCC) from the Area Health Resource Files (AHRF), with counties classified as "metropolitan" (RUCC 1, 2, or 3), "rural adjacent" (RUCC 4, 6, or 8), or "rural remote" (RUCC 5, 7, or 9). ${ }^{17}$ We calculated county overdose rates as the per capita rate of overdose deaths due to any drug using data from the Centers for Disease Control and 
Prevention $^{18}$; we calculated poverty rates based on the American Community Survey $(\mathrm{ACS})^{19}$; we obtained primary care health professional shortage areas (HPSAs) information from the AHRF. ${ }^{20}$

\section{Analytic Approach}

Analyses were conducted at the episode level. We first calculated the number and unadjusted percentages of long-term opioid therapy episodes overall and by individual and county-level characteristics. We then calculated the number and percentage of episodes where naloxone was co-prescribed overall and by individual and county-level characteristics. Finally, we conducted a multivariable logistic regression analysis examining naloxone co-prescribing during long-term opioid therapy episodes as a function of individual, prescriber, prescription, and county-level factors, using state fixed effects and controlling for opioid episode duration using the $\log$ of number of episode days. We reported adjusted odds ratios along with $95 \%$ confidence intervals, and clustered at the individual level to account for individuals with multiple episodes.

\section{RESULTS}

We identified 5,129,159 unique patients with 6,060,728 longterm opioid therapy episodes in 2017-2018. Nearly $60 \%$ of episodes were among women, and over half $(61.3 \%)$ were among individuals over 55 years of age (Table 1). The largest percentage of long-term opioid therapy episodes were paid for by Medicare $(40.9 \%)$, followed by commercial insurance $(27.2 \%)$, by other insurance $(14.9 \%)$, and by Medicaid $(13.4 \%)$. Less than $5 \%$ of long-term opioid therapy episodes were paid for with cash. More than half $(58.0 \%)$ of episodes included two or more prescribers, $13.4 \%$ involved concomitant benzodiazepine therapy, and $8.5 \%$ involved high-dose opioid prescribing. Over $80 \%$ (83.9\%) of episodes were prescribed by clinicians in metropolitan counties. Adult primary care physicians (PCPs) were responsible for prescribing $47.6 \%$ of episodes; pain/anesthesia specialists for $21.4 \%$; and primarily nurse practitioners (NPs) or physician's assistants (PAs) for $19.0 \%$.

Naloxone co-prescribing occurred in 136,870 long-term opioid therapy episodes (2.3\%; Table 2$)$. In the multivariable logistic regression model, we found that compared to the $2.7 \%$ of individuals aged 26-35 years with long-term opioid therapy episodes who received naloxone, individuals $36-45$ years (2.9\%; aOR $1.05,95 \% \mathrm{CI} 1.02$ to 1.08$)$ and $46-55$ years (2.9\%; aOR 1.04, 95\%CI 1.01 to 1.06 ) had higher odds of being co-prescribed naloxone; individuals $18-25$ years $(2.1 \%$; aOR $0.91,95 \%$ CI 0.85 to 0.96$)$ and $56-65$ years $(2.5 \%$; aOR $0.93,95 \%$ CI 0.90 to 0.95 ) had lower odds. However, the greatest difference was among individuals over 65 years, who had substantially lower odds of being co-prescribed naloxone ( $1.4 \%$ aOR $0.59,95 \% \mathrm{CI} 0.58$ to 0.61 ).
Table 1 Characteristics of Long-term Opioid Treatment Episodes 2017-2018

\begin{tabular}{ll}
\hline \hline & $N(\%)$ \\
\hline Total & $6,060,728(100)$ \\
Gender & \\
Female & $3,613,084(59.6)$ \\
Male & $2,447,644(40.4)$ \\
Age cohort & \\
12-17 & $8,923(0.1)$ \\
18-25 & $65,731(1.1)$ \\
26-35 & $371,632(6.1)$ \\
$36-45$ & $704,189(11.6)$ \\
46-55 & $1,194,438(19.7)$ \\
56-65 & $1,603,872(26.5)$ \\
66+ & $2,111,943(34.8)$ \\
Primary opioid episode payer & \\
Medicare & $2,475,988(40.9)$ \\
Medicaid & $811,055(13.4)$ \\
Commercial & $1,651,028(27.2)$ \\
Cash & $219,166(3.6)$ \\
Other & $903,491(14.9)$ \\
Concomitant benzodiazepine prescription & \\
Yes & $813,211(13.4)$ \\
No & $5,247,517(86.6)$ \\
High-dose episode & \\
Yes & $515,621(8.5)$ \\
No & $5,545,107(91.5)$ \\
Naloxone co-prescribed & \\
Yes & $136,870(2.3)$ \\
No & $5,923,858(97.7)$ \\
Prescriber specialty & \\
PCP adult & $2,884,379(47.6)$ \\
Pain specialist/anesthesia & $1,294,993(21.4)$ \\
PA/NP & $1,150,098(19.0)$ \\
Oncology & $158,180(2.6)$ \\
Other & $573,078(9.5)$ \\
Multiple opioid prescribers & $3,512,959(58.0)$ \\
Yes & $2,547,769(42.0)$ \\
No & \\
County urban-rural status & $5,084,565(83.9)$ \\
Metropolitan & $597,566(9.9)$ \\
Rural adjacent & $378,597(6.2)$ \\
Rural remote & $5,849,976(96.5)$ \\
Health professional shortage area & $210,752(3.5)$ \\
Yes & \\
No & \\
\hline &
\end{tabular}

Episodes covered by Medicaid (3.7\%; aOR 1.87, 95\% CI 1.84 to 1.90$)$ or Medicare $(2.3 \%$; aOR $1.48,95 \% \mathrm{CI} 1.46$ to 1.51) had higher odds of being co-prescribed naloxone compared to the $2.0 \%$ co-prescribing rate seen in episodes covered by commercial insurance. Individuals who had a primary payer of other insurance $(1.6 \%$; aOR $0.81,95 \% \mathrm{CI} 0.79$ to 0.83 ) or cash pay $(1.4 \%$; aOR $0.77,95 \%$ CI 0.74 to 0.80$)$ had lower odds of naloxone co-prescribing.

Compared to the $1.2 \%$ of long-term opioid therapy episodes where naloxone was prescribed by an adult PCP, episodes in which the prescriber was a pain or anesthesia specialist $(3.8 \%$; aOR $2.47,95 \% \mathrm{CI} 2.43$ to $2.51)$ or a PA or NP $(3.7 \%$; aOR $2.29,95 \%$ CI 2.26 to 2.33) had higher odds of involving co-prescribed naloxone (Table 2). Naloxone was also co-prescribed more commonly in episodes with multiple prescribers compared with a single opioid prescriber (2.9\% vs. $1.3 \%$; aOR 1.40 ; $95 \% \mathrm{CI} 1.38$ to 1.41 ). Odds of naloxone co-prescribing were higher among high-dose opioid episodes $(7.7 \%$ vs. 
Table 2 Individual and County Characteristics Associated with Naloxone Co-prescribing During Long-term Opioid Treatment Episodes 2017-2018

\begin{tabular}{|c|c|c|c|}
\hline & $\begin{array}{l}N \text { of episodes } \\
\text { with } \\
\text { naloxone co- } \\
\text { prescribing }\end{array}$ & $\begin{array}{l}\text { Unadjusted } \\
\text { rate of long- } \\
\text { term opioid } \\
\text { treatment epi- } \\
\text { sodes with nal- } \\
\text { oxone co- } \\
\text { prescribed (\%) }\end{array}$ & $\operatorname{aOR}(95 \% \mathrm{CI})$ \\
\hline Total & 136,870 & 2.3 & - \\
\hline Gender & & & \\
\hline $\begin{array}{l}\text { Female } \\
\text { Male }\end{array}$ & $\begin{array}{l}80,721 \\
56,149\end{array}$ & $\begin{array}{l}2.2 \\
2.3\end{array}$ & $\begin{array}{l}\text { REF } \\
1.00(0.99, \\
1.01)\end{array}$ \\
\hline $\begin{array}{l}\text { Age cohort } \\
12-17\end{array}$ & 184 & 2.1 & $0.84(0.72$ \\
\hline 18.25 & 1407 & 2.1 & $\begin{array}{l}0.91(0.85, \\
0.96)\end{array}$ \\
\hline $26-35$ & 9995 & 2.7 & REF \\
\hline $36-45$ & 20,548 & 2.9 & $\begin{array}{l}1.05(1.02, \\
1.08)\end{array}$ \\
\hline $46-55$ & 34,607 & 2.9 & $\begin{array}{l}1.04(1.01, \\
1.06)\end{array}$ \\
\hline $56-65$ & 39,934 & 2.5 & $\begin{array}{l}0.93(0.90, \\
0.95)\end{array}$ \\
\hline $66+$ & 30,195 & 1.4 & $\begin{array}{l}0.59(0.58 \\
0.61)\end{array}$ \\
\hline \multicolumn{4}{|l|}{$\begin{array}{l}\text { Primary opioid } \\
\text { episode payer }\end{array}$} \\
\hline Medicare & 55,934 & 2.3 & $\begin{array}{l}1.48(1.46, \\
1.51)\end{array}$ \\
\hline Medicaid & 30,241 & 3.7 & $\begin{array}{l}1.87(1.84, \\
1.90)\end{array}$ \\
\hline Commercial & 33,309 & 2.0 & REF \\
\hline Cash & 3083 & 1.4 & $\begin{array}{l}0.77(0.74, \\
0.80)\end{array}$ \\
\hline Other & 14,303 & 1.6 & $\begin{array}{l}0.81(0.79 \\
0.83)\end{array}$ \\
\hline \multicolumn{4}{|l|}{$\begin{array}{l}\text { Concomitant } \\
\text { benzodiazepine }\end{array}$} \\
\hline Yes & 28,630 & 3.5 & $\begin{array}{l}1.12(1.10, \\
1.14)\end{array}$ \\
\hline $\begin{array}{l}\text { No } \\
\text { High-dose } \\
\text { episode }\end{array}$ & 108,240 & 2.1 & REF \\
\hline Yes & 39,809 & 7.7 & $\begin{array}{l}3.19(3.15, \\
3.23)\end{array}$ \\
\hline $\begin{array}{l}\text { No } \\
\text { Prescriber } \\
\text { specialty }\end{array}$ & 97,061 & 1.8 & REF \\
\hline PCP adult & 35,534 & 1.2 & REF \\
\hline $\begin{array}{l}\text { Pain specialist/ } \\
\text { anesthesia }\end{array}$ & 48,970 & 3.8 & $\begin{array}{l}2.47(2.43, \\
2.51)\end{array}$ \\
\hline PA/NP & 42,969 & 3.7 & $\begin{array}{l}2.29(2.26, \\
2.33)\end{array}$ \\
\hline Oncology & 3524 & 2.2 & $\begin{array}{l}1.06(1.02, \\
1.10)\end{array}$ \\
\hline Other & 5873 & 1.0 & $\begin{array}{l}0.92(0.89, \\
0.95)\end{array}$ \\
\hline \multicolumn{4}{|l|}{$\begin{array}{l}\text { Multiple opioid } \\
\text { prescribers }\end{array}$} \\
\hline Yes & 102,609 & 2.9 & $\begin{array}{l}1.40(1.38, \\
1.41)\end{array}$ \\
\hline $\begin{array}{l}\text { No } \\
\text { County } \\
\text { overdose rate } \\
\text { quartile }\end{array}$ & 34,261 & 1.3 & REF \\
\hline $\begin{array}{l}1 \text { st quartile } \\
\text { (lowest OD } \\
\text { rate) }\end{array}$ & 24,707 & 1.6 & REF \\
\hline 2nd quartile & 34,059 & 2.2 & $\begin{array}{l}1.18 \text { (1.16, } \\
1.21)\end{array}$ \\
\hline 3rd quartile & 42,675 & 2.8 & $\begin{array}{l}1.24(1.21, \\
1.26)\end{array}$ \\
\hline
\end{tabular}

(continued on next page)
Table 2. (continued)

\begin{tabular}{|c|c|c|c|}
\hline & $\begin{array}{l}N \text { of episodes } \\
\text { with } \\
\text { naloxone co- } \\
\text { prescribing }\end{array}$ & $\begin{array}{l}\text { Unadjusted } \\
\text { rate of long- } \\
\text { term opioid } \\
\text { treatment epi- } \\
\text { sodes with nal- } \\
\text { oxone co- } \\
\text { prescribed (\%) }\end{array}$ & $\overline{\operatorname{aOR}(95 \% \mathrm{CI})}$ \\
\hline $\begin{array}{l}\text { 4th quartile } \\
\text { (highest OD } \\
\text { rate) } \\
\text { County poverty } \\
\text { rate }\end{array}$ & 35,429 & 2.3 & $\begin{array}{l}1.13(1.10, \\
1.15)\end{array}$ \\
\hline $\begin{array}{l}1 \text { st quartile } \\
\text { (lowest poverty } \\
\text { rate) }\end{array}$ & 35,931 & 2.4 & $\begin{array}{l}0.92(0.90 \\
0.94)\end{array}$ \\
\hline 2nd quartile & 36,825 & 2.5 & $\begin{array}{l}1.01(0.99, \\
1.03)\end{array}$ \\
\hline 3rd quartile & 32,201 & 2.1 & $\begin{array}{l}0.96(0.94, \\
0.98)\end{array}$ \\
\hline $\begin{array}{l}\text { 4th quartile } \\
\text { (highest poverty } \\
\text { rate) } \\
\text { County rural- } \\
\text { urban status } \\
\text { (RUCC) }\end{array}$ & 31,913 & 2.1 & REF \\
\hline Metropolitan & 120,960 & 2.4 & REF \\
\hline Rural adjacent & 10,188 & 1.7 & $\begin{array}{l}0.85(0.83 \\
0.87)\end{array}$ \\
\hline Rural remote & 5722 & 1.5 & $\begin{array}{l}0.78(0.76 \\
0.81)\end{array}$ \\
\hline \multicolumn{4}{|l|}{$\begin{array}{l}\text { Health } \\
\text { professional } \\
\text { shortage area }\end{array}$} \\
\hline No & 133,689 & 2.3 & REF \\
\hline Yes & 3181 & 1.5 & $\begin{array}{l}0.85(0.81, \\
0.88)\end{array}$ \\
\hline
\end{tabular}

The model also includes state fixed effects and controls for log of the episode days. Standard errors are adjusted for individual-level clustering

$1.8 \%$; aOR 3.19 , 95\% CI 3.15 to 3.23 ) and when concomitant benzodiazepines were prescribed during the episode (3.5\% vs. $2.1 \%$; aOR $1.12,95 \%$ CI 1.10 to 1.14 ).

The odds of naloxone co-prescribing were lower in rural adjacent $(1.7 \%$; aOR $0.85,95 \% \mathrm{CI} 0.83$ to 0.87$)$ and rural remote counties $(1.5 \%$; aOR $0.78,95 \% \mathrm{CI} 0.76$ to 0.81$)$ compared to metropolitan counties (2.4\%). Counties designated as health professional shortage areas had lower odds of naloxone co-prescribing (1.5\%; aOR $0.85,95 \%$ CI 0.81 to 0.88$)$ compared to counties without that designation (2.3\%). Compared to counties in the lowest quartile for overdose death rates, all other county quartiles had higher odds of naloxone co-prescribing. There was no clear association between naloxone coprescribing and county poverty rate (Table 2 ).

\section{DISCUSSION}

Our examination of naloxone co-prescribing to individuals receiving long-term opioid therapy found extremely low rates of naloxone co-prescribing in 2017-2018: in only about 1 in every 44 episodes with 90 or more days of opioid therapy was naloxone also co-prescribed. These low rates of naloxone coprescribing are consistent with prior studies among 
commercially insured individuals and those in the Medicare Part D program. ${ }^{10,21}$ These findings carry important implications for clinical practice and opioid overdose prevention; they also highlight significant opportunities to expand naloxone coprescribing among patients receiving opioids.

While recent years have seen a dramatic increase in overdose deaths involving synthetic opioids such as illicitly made fentanyl ${ }^{22}$ prescription opioid analgesics remain commonly involved in overdose deaths. In 2017-2018, prescription opioids were involved in approximately one-third of fatal opioid-related overdoses, ${ }^{1}$ and over $40 \%$ of individuals experiencing non-fatal overdoses had filled an opioid prescription in the preceding 12 months. ${ }^{23}$ Among individuals receiving long-term opioid therapy, individuals receiving high doses of opioids or concomitant benzodiazepine therapy have a significantly higher overdose risk. ${ }^{24}$ Increasing naloxone coprescribing to these individuals is one relatively easy action that can be taken to potentially decrease opioid overdose deaths. ${ }^{6}$ Policy efforts such as mandatory naloxone coprescribing laws may be one approach to rapidly increasing the availability of naloxone. ${ }^{25}$ However, studies have not yet fully examined to what extent such policies increase naloxone co-prescribing to high-risk populations compared with all individuals filling opioid prescriptions. ${ }^{25}$

Among individuals receiving long-term opioid therapy, we found that those with additional risk for overdose, such as concomitant benzodiazepine therapy or receiving high doses of opioids ${ }^{2}$ as well as those with prescribers in counties with higher rates of fatal overdoses, were more likely to be coprescribed naloxone. It is encouraging that clinicians appear to be more likely to co-prescribe naloxone to these higher risk individuals. However, we note that co-prescribing rates among these groups were lower than one might hope for, given the elevated overdose risk: only approximately $7.7 \%$ of long-term high-dose opioid episodes and 3.5\% of concomitant benzodiazepine episodes involved co-prescribed naloxone. Such low rates suggest the ongoing need to get naloxone into the hands of individuals at risk for overdose and their loved ones or caregivers. A range of approaches are needed, including increasing support and expansion of opioid education and naloxone distribution programs, ${ }^{26}$ enhancing pharmacist and prescriber education about naloxone, identifying and educating patients at elevated overdose risk, and addressing pharmacists' and providers' perceived barriers to distributing and prescribing naloxone. ${ }^{27-29}$

Consistent with other studies, ${ }^{15,21}$ we found higher rates of naloxone co-prescribing among patients prescribed long-term opioid therapy by pain/anesthesia doctors and nurse practitioners/physician assistants as well as higher rates in metropolitan counties. Interestingly, we also found naloxone co-prescribing rates followed an inverse U-pattern with respect to age, peaking with the $46-55$ age group. This pattern closely matches the age trajectory of fatal overdose rates involving prescription opioids (i.e., natural and semisynthetic opioids and methadone), which also increases monotonically until the $45-54$ age group before steadily declining. ${ }^{1}$ While naloxone co-prescribing appears to target higher risk groups overall, the low rates of co-prescribing among individuals over the age of 65 are somewhat concerning given the higher rates of potentially inappropriate opioid prescribing to older individuals and research documenting that prescription opioids play a role as a major cause of opioid-related death in older adults. ${ }^{30,31}$

Our findings must be considered in the context of the study's limitations. While we use the term naloxone co-prescribing, consistent with other studies examining naloxone pharmacy claims, ${ }^{10,32}$ we only observe dispensed prescriptions. As a result, we do not know to what extent patients are not receiving naloxone prescriptions from their clinicians or are choosing not to fill prescriptions they have received. Individuals not filling a naloxone prescription may also have obtained naloxone from another source, such as a community naloxone distribution program or a family member or have filled a naloxone prescription prior to the observed period. We note, however, that we are able to examine naloxone prescriptions across all types of payers. This is a significant contribution, as our results suggest that analyses of co-prescribing limited to one type of payer (e.g., commercial insurance, Medicaid, Medicare) may not generalize to other payers. The 2 years of data is also insufficient for us to examine the effects of state policies that may influence naloxone co-prescribing.

\section{CONCLUSION}

Receiving long-term opioid therapy, in particular at higher doses or in combination with benzodiazepines, increases risk for opioid-related overdose. Co-prescription of naloxone represents a tangible clinical action that can be taken to help prevent opioid overdose and is one important strategy to reduce the risks of harms associated with chronic opioid use that complements other strategies such as using the lowest opioid dose and shortest duration of opioid therapy needed for adequate pain control, avoiding the use of alcohol and other drugs while receiving opioid therapy, and minimizing the concurrent use of medications such as benzodiazepines and gabapentinoids that can increase overdose risk. However, despite recommendations by CDC, HHS, and professional associations to consider co-prescribing naloxone to patients at increased risk for opioid overdose, ${ }^{5-7}$ we found that coprescribing rates remain low overall. Encouragingly, we found that co-prescribing was higher among patients with elevated risk factors for opioid overdose, suggesting that the decision to co-prescribe naloxone is partially determined by risk. Implementing policies and interventions targeting this group of patients, their prescribers, and their pharmacists may be a particularly opportune approach to increasing naloxone coprescribing to individuals at the highest risk. Opportunities remain to expand co-prescribing of naloxone to patients receiving long-term opioid therapy. Expanded education and 
use of academic detailing for prescribers and pharmacists on naloxone co-prescription, ${ }^{33-36}$ electronic health record alerts to prompt clinicians on naloxone co-prescribing when risk factors are present, and payment policy changes to reduce cost barriers for patients are strategies that states, insurers, and health systems should consider to facilitate increased provision of naloxone.

Acknowledgments: The authors would like to thank Mary Vaiana and Hilary Peterson for feedback on prior versions of this manuscript.

Corresponding Author: Bradley D. Stein, $M D, P h D$; University of Pittsburgh School of Medicine, Pittsburgh, PA, USA (e-mail: stein@rand.org).

Funding This work was supported by the National Institute on Drug Abuse (NIDA) through R21 DA045950 (Smart, PI), RO1 DA045055 (Stein, PI), and P50 DA046351 (Stein, PI) and the National Center for Injury and Prevention Control (NCIPC) RO1 CEOO2999 (Powell, PI).

\section{Declarations:}

Conflict of Interest: The authors declare that they do not have a conflict of interest.

\section{REFERENCES}

1. Wilson N, Kariisa M, Seth P, Smith HT, Davis NL. Drug and opioidinvolved overdose deaths - United States, 2017-2018. MMWR Morb Mortal Wkly Rep. 2020;69(11):290-297.

2. Rose AJ, Bernson D, Chui KKH, et al. Potentially inappropriate opioid prescribing, overdose, and mortality in Massachusetts, 2011-2015. J Gen Intern Med. 2018;33(9): 1512-1519.

3. Barnett ML, Olenski AR, Jena AB. Opioid-prescribing patterns of emergency physicians and risk of long-term use. $\mathrm{N}$ Engl $\mathrm{J}$ Med. 2017;376(7):663-673.

4. Coyle DT, Pratt CY, Ocran-Appiah J, Secora A, Kornegay C, Staffa J. Opioid analgesic dose and the risk of misuse, overdose, and death: A narrative review. Pharmacoepidemiol Drug Saf. 2018;27(5):464-472.

5. Public Policy Statement on the Use of Naloxone for the Prevention of Opioid Overdose Deaths. Chevy Chase, MD: American Society of Addiction Medicine; Undated: https://www.asam.org/docs/defaultsource/public-policy-statements/use-of-naloxone-for-the-prevention-ofopioid-overdose-deaths-final.pdf. Accessed May 15, 2020.

6. U.S. Health and Human Services. Naloxone: The Opioid Reversal Drug that Saves Lives. https://www.hhs.gov/opioids/sites/default/files/ 2018-12/naloxone-coprescribing-guidance.pdf. Published undated. Accessed May 11, 2020.

7. Dowell D, Haegerich TM, Chou R. CDC Guideline for prescribing opioids for chronic pain-United States, 2016. JAMA. 2016;315(15): 1624-1645.

8. Boyer EW. Management of opioid analgesic overdose. N Engl J Med. 2012;367(2): 146-155

9. Abouk R, Pacula RL, Powell D. Association between state laws facilitating pharmacy distribution of naloxone and risk of fatal overdose. JAMA Intern Med. 2019.

10. Jones CM, Compton W, Vythilingam M, Giroir B. Naloxone coprescribing to patients receiving prescription opioids in the Medicare Part D Program, United States, 2016-2017. JAMA. 2019;322(5):462-464.

11. Roberts AW. Naloxone prescribing among frequent opioid prescribers in Medicare Part D from 2013 to 2017: A retrospective study. J Gen Intern Med. 2020

12. Frank RG, Fry CE. The impact of expanded Medicaid eligibility on access to naloxone. Addiction. 2019;114(9): 1567-1574

13. Guy GP, Jr., Haegerich TM, Evans ME, Losby JL, Young R, Jones CM. Vital Signs: Pharmacy-based naloxone dispensing - United States, 20122018. MMWR Morb Mortal Wkly Rep. 2019;68(31):679-686.
14. Sohn M, Talbert JC, Huang Z, Lofwall MR, Freeman PR. Association of naloxone coprescription laws with naloxone prescription dispensing in the United States. JAMA Netw Open. 2019;2(6):e196215.

15. Smart R, Geiger CK, Jones CM, Stein BD. An observational study of retail pharmacy naloxone prescriptions: differences across provider specialties and patient populations. J Gen Intern Med. 2019.

16. IQVIA: Real World Data and Insights. https://www.iqvia.com/solutions/ real-world-evidence/real-world-data-and-insights. Accessed July 13, 2020.

17. National Center for Health Statistics. 2013 NCHS Urban-Rural Classification Scheme for Counties; Vol 2. Atlanta, GA: Centers for Disease Control and Prevention; 2014.

18. Centers for Disease Control Prevention. Drug Overdose Deaths. https:// www.cdc.gov/drugoverdose/data/statedeaths.html. Published 2020. Accessed May 20, 2020.

19. U.S. Census Bureau. Selected housing characteristics, 2007-2011 American Community Survey 5-year estimates. 2011.

20. U.S. Department of Health and Human Services Health Resources and Services Administration. Area Health Resources Files. 2006-2019.

21. Follman S, Arora VM, Lyttle C, Moore PQ, Pho MT. Naloxone prescriptions among commercially insured Individuals at hgh risk of opioid overdose. JAMA Netw Open. 2019;2(5):e193209.

22. Centers for Disease Control Prevention. Reported Law Enforcement Encounters Testing Positive for Fentanyl Increase Across US. https:// www.cdc.gov/drugoverdose/data/fentanyl-le-reports.html. Published 2016. Accessed May 20, 2020.

23. Chatterjee A, Larochelle MR, Xuan Z, et al. Non-fatal opioid-related overdoses among adolescents in Massachusetts 2012-2014. Drug Alcohol Depend. 2019;194:28-31.

24. Dunn KM, Saunders KW, Rutter CM, et al. Opioid prescriptions for chronic pain and overdose: A cohort study. Ann Intern Med. 2010;152(2):85-92.

25. Green TC, Davis C, Xuan Z, Walley AY, Bratberg J. Laws mandating coprescription of naloxone and their impact on naloxone prescription in five US states, 2014-2018. Am J Public Health. 2020;110(6):881-887.

26. Wheeler E, Jones TS, Gilbert MK, Davidson PJ. Opioid overdose prevention programs providing naloxone to laypersons - United States, 2014. MMWR Morb Mortal Wkly Rep. 2015;64(23):631-635.

27. Thakur T, Frey M, Chewning B. Pharmacist roles, training, and perceived barriers in naloxone dispensing: A systematic review. J Am Pharm Assoc (2003). 2020;60(1):178-194.

28. Martino JG, Smith SR, Rafie S, Rafie S, Marienfeld C. Physician and pharmacist: Attitudes, facilitators, and barriers to prescribing naloxone for home rescue. Am J Addict. 2020;29(1):65-72

29. Bounthavong $\mathbf{M}$, Suh $\mathbf{K}$, Christopher MLD, Veenstra DL, Basu A, Devine EB. Providers' perceptions on barriers and facilitators to prescribing naloxone for patients at risk for opioid overdose after implementation of a national academic detailing program: A qualitative assessment. Res Social Adm Pharm. 2020;16(8):1033-1040.

30. Unick GJ, Ciccarone D. US regional and demographic differences in prescription opioid and heroin-related overdose hospitalizations. Int $\mathrm{J}$ Drug Policy. 2017;46:112-119.

31. Rose AJ, McBain R, Schuler MS, et al. Effect of age on opioid prescribing, overdose, and mortality in Massachusetts, 2011 to 2015. J Am Geriatr Soc. 2019;67(1):128-132.

32. Xu J, Davis CS, Cruz M, Lurie P. State naloxone access laws are associated with an increase in the number of naloxone prescriptions dispensed in retail pharmacies. Drug Alcohol Depend. 2018;189:37-41.

33. Behar E, Rowe C, Santos GM, Santos N, Coffin PO. Academic detailing pilot for naloxone prescribing among primary care providers in San Francisco. Fam Med. 2017;49(2):122-126.

34. Marino R, Landau A, Lynch M, Callaway C, Suffoletto B. Do electronic health record prompts increase take-home naloxone administration for emergency department patients after an opioid overdose? Addiction. 2019;114(9):1575-1581.

35. Bounthavong $\mathbf{M}$, Harvey MA, Wells DL, et al. Trends in naloxone prescriptions prescribed after implementation of a National Academic Detailing Service in the Veterans Health Administration: A preliminary analysis. J Am Pharm Assoc (2003). 2017;57(2S):S68-S72.

36. Furlan A, Zhao J, Voth J. Evaluation of an innovative tele-education intervention in chronic pain management for primary care clinicians practicing in underserved areas. J Telemed Telecare. 2018;24:1357633X18782090

Publisher's Note: Springer Nature remains neutral with regard to jurisdictional claims in published maps and institutional affiliations. 